\title{
Poverty and Inequality in the First Decade of South Africa's Democracy: What can be Learnt from Panel Data from KwaZulu-Natal?
}

\author{
Jorge Agüero ${ }^{a}$, Michael R. Carter ${ }^{\mathrm{b}}$ and Julian May, ${ }^{\mathrm{c}, *}$ \\ ${ }^{a}$ Department of Economics, University of California, \\ Riverside, 4108, Sproul Hall, Riverside, CA 92521, USA \\ ${ }^{\mathrm{b}}$ Department of Agricultural and Applied Economics, \\ University of Wisconsin, Madison, 421 Taylor Hall, 427 Lorch \\ Street, Maddison, WI 53706, USA and \\ 'School of Development Studies, University of KwaZulu- \\ Natal, Memorial Tower Building, King George V Ave, Durban, \\ South Africa
}

Despite striking indicators depicting high per capita Gross Domestic Product together with poor social indicators, changes in the incidence and severity of money-metric poverty in South Africa since 1993 have been a source of debate. Household surveys suggest that poverty appears to have persisted during the 1990s, with perhaps some improvement since 2000. Inequality remains high, and is probably widening, but there has been delivery in terms of social services such as water and electricity. Panel data that track the circumstances of the same people contribute

\footnotetext{
* Corresponding author: Julian May, School of Development Studies, University of KwaZulu-Natal, Memorial Tower Building, King George V Aue, Durban, South Africa. Telephone: +27 31 2602841. E-mail: mayj@ukzn.ac.za. An earlier version of this paper was presented to 'South African Economic Policy under Democracy: A Ten Year Review' held at Mostertsdrift in Stellenbosch, 28 October 2005. Useful comments received from Murray Leibbrandt and Geeta Kingdon, and three anonymous referees, are gratefully acknowledged and the usual disclaimers apply. The data set reported here is an outcome of a collaborative project among researchers at the University of KwaZulu-Natal, the University of Wisconsin-Madison, the London School of Hygiene \& Tropical Medicine, the Norwegian Institute of Urban and Regional Studies, the International Food Policy Research Institute (IFPRI) and the South African Department of Social Development. In addition to these institutions, financial support was provided by the Department for International Development-South Africa (DFID-SA), the United States Agency for International Development under agreement No. LAG-A-00-96-90016-00 through the BASIS Collaborative Research Support Program, the Mellon Foundation and a National Research Foundation/Norwegian Research Council grant to the University of KwaZuluNatal.
}

(C) The author 2007. Published by Oxford University Press on behalf of the Centre for the Study of African Economies. All rights reserved. For permissions, please email: journals.permissions@oxfordjournals.org 
towards a deeper understanding of the complex story of poverty and inequality in South Africa. Data from the KwaZulu-Natal Income Dynamics Study (KIDS) collected between 1993 and 2004 show increasing poverty and inequality in the mid-1990s, with a partial reversal of some of these trends in the post-1998 period. The improved well-being of at least some next-generation households is a hopeful sign in these data. In addition, government transfers do seem to have contributed towards dampening the impact of market-generated inequality, reducing the spread of the expenditure distribution and lifting up the very lowest part of the distribution. In particular, the introduction of the Child Support Grant has dramatically increased the number of recipients of grants. This is reflected in the KIDS data, which show that the amount of transfers per-household has doubled.

JEL Classification: I32, D63, J62, C23, N37

\section{Introduction}

During the months leading up to the 10-year celebrations of South Africa's democracy, an intense debate took place concerning poverty and inequality trends in the post-apartheid era. This debate was complicated by the multitude of methodologies applied to the analysis of poverty and inequality, as well as by data problems identified in the available official statistics. Representatives of the South African government questioned the findings of both the official statistics agency and other sources. Suggestions that poverty and inequality had increased were countered by referring to improvements in social expenditure, service delivery and the impact that these had on the 'social wage.'

Although a critical and comparative review of the various studies and their methodologies seems a necessity at some point, alternative data sources provide an opportunity to triangulate and contribute towards an understanding of the complex story of poverty and inequality in South Africa between 1993 and 2004. Of particular use are studies that have tracked the circumstances of the same people during the period under review. Arguing the need for such panel data, May and Roberts (2001) described a panel data set that had been made available to researchers earlier that year. These data, known as the KwaZulu-Natal Income Dynamics Study (KIDS), were derived from households first surveyed in 1993 as a part of the national 
784 Jorge Agüero et al.

Project for Statistics on Living Standards and Development (PSLSD) and re-interviewed in 1998. A re-survey of the KIDS households in 2004 extends the information that is available by a further six years and now provides a three period panel study that spans the first decade of South Africa's democracy and the introduction of many policies intended to reduce poverty.

This paper first briefly summarises some of the existing information on trends in poverty, inequality, employment and access to services from various data sources. The paper then describes the three waves of data collection for KIDS and goes on to analyse transitions made by the surveyed households in terms of economic well-being and access to services and grants. The paper concludes by identifying important areas for further research that might improve the analysis and interpretation of the changes in poverty in the first decade of South Africa's transition.

\section{Income Distribution and Welfare Changes 1993-2004: Evidence from Official Statistics}

At PPP $\$ 11,240$ per annum in 2001, South Africa's per capita GDP corrected for purchasing power parity (PPP) now places it as one of the 50 wealthiest nations and among the 35 largest economies in the world. However, in terms of the absolute numbers of people living on less than PPP\$2, the UNDP ranks South Africa 16th out of the 67 countries for which poverty measurements are reported, despite it ranking 10th among these countries in terms of GDP per capita (UNDP, 2006). South Africa is also ranked 120th of 175 countries in terms of its Human Development Index (HDI) in 2004, down from its ranking of 93rd in 1992 (UNDP, 2003). South Africa is one of a handful of countries that has experienced a decline in the HDI since 1995. This decline is largely the result of high levels of adult mortality. South Africans now have life expectancies among the 30 worst in the world. Projections of mortality suggest that these will deteriorate further as deaths from the AIDS pandemic increase (UNDP, 2003; Dorrington et al., 2004).

Despite these striking social indicators, changes in the incidence and severity of money-metric poverty since 1993 have been a source of debate. Using the results of official Income and Expenditure Surveys (IES), Statistics South Africa suggests that both poverty and inequality have increased (Stats SA, 2002). However, although the average annual 
per capita income in the 1995 IES of R12,135 adjusted to 2000 prices appears higher than the per capita income of R11,755 per annum reported in the 2000 IES, this difference is not statistically significant. Furthermore, many analysts have raised serious concerns with the quality of the data collected by this survey, pointing to methodological and weighting problems and evidence of sloppy fieldwork and data processing (Meth and Dias, 2004: p. 61; van der Berg and Louw, 2003: p. 2).

A number of researchers have attempted to manage some of these data quality problems. Using methodologies to derive a cost-of-calories poverty line, Hoogeveen and Özler (2005: p. 32) estimate that 12.6 million South Africans were living on less than PPP $\$ 1$ per day in 1995, and 14.4 million in 2000, an increase of 1.8 million people. They also estimate 22.9 million South Africans were living on less than PPP $\$ 2$ per day in 1995, a number that rose by 2.3 million to a total of 25.2 million by 2000 . They also show an increase in both the poverty gap index and the severity measure of poverty (0.11-0.13 and 0.05-0.07 respectively), while the headcount index increased slightly from 0.32 in 1995 to 0.34 in 2000 using the PPP $\$ 2$ per day poverty line. Using data from other official statistics such as the October Household Survey (OHS) and General Household Survey (GHS), Meth and Dias (2004) employ a mix of procedures to adjust for data problems and conclude that the case for an increase in the numbers of people in poverty over the late 1990s seems convincing. The numbers of people in the lower expenditure group, identified as encompassing the potentially poor, increased by about 3.5 million people between 1997 and 2002. Meth and Dias estimate that there were 17.4 million people in poverty in 2002, resulting in a headcount index of 0.38 .

In an input paper to the 2005 Report of the Development Bank of Southern Africa, May and Woolard (2005) use a version of the 2000 IES that was cleaned by Global Insight and subsequently by Woolard and then re-weighted by Simkins (as described in Simkins, 2004) and use the Household Subsistence Level estimated separately for urban and rural areas. Their results are shown in Table 1.

All these measures support the argument that poverty increased in South Africa between 1995 and 2000. The poverty headcount rose, as did the average depth of poverty as measured by the income gap measure. In addition, the Sen poverty index (which increases with the headcount, the income gap and the extent of inequality among the poor) also rose. 
786 Jorge Agüero et al.

Table 1: Poverty Measures Based on the Household Subsistence Level, 1995 and 2000

1995

2000

Headcount index

0.32

0.49

Income gap measure

0.12

0.22

Sen Poverty Index

0.24

0.39

Source: May and Woolard (2005) calculations on IES 1995 and IES 2000.

Although data and measures based on private consumption and income consistently show higher poverty rates, people's actual material well-being may have been improved by increased social spending and improved public services and infrastructure. van der Berg and Burger (2002: pp. 10-11) show that the share of social spending allocated to the African population increased from $51 \%$ in the immediate transition period to $80 \%$ in 1997 . To the extent that they have been beneficiaries, this re-allocation will have had an impact on the incomes of the lowest income groups. In an effort to account for these effects, Meth and Dias (2004) attempt to account for the impact of cash and non-cash transfers to the poor from government in the form of grants as well as subsidies to water, electricity, health care, housing, sanitation, education and transport. While their calculations assume that subsidies were perfectly targeted on the poor, they argue that the number of poor people increased by 2.7 million (not the 3.2 million indicated when only private income is considered) over the 1997-2002 period.

Turning to measures of inequality, May and Woolard (2005) review a range of estimates. Most show increasing inequality, with the exception of their own calculations and those of Fedderke et al. (2003), both of which rely on household expenditure data. May and Woolard (2005) note that in all cases, South Africa's Gini coefficient remains among the highest in the world. Hoogeveen and Özler (2005: p. 15) show that the Gini had increased from 0.56 in 1995 to 0.58 in 2000.

van der Berg and Burger (2002: pp. 10-11) attempt to adjust inequality measures by taking into account the shifts in social 
spending mentioned earlier. Noting that per capita incomes of the African elite have almost caught up with the white population, they calculate a pre-tax, pre-transfer Gini coefficient of 0.66 . But when income is adjusted for South Africa's relatively progressive taxes and strongly progressive non-cash transfers, the Gini coefficient drops to 0.44. In particular, van der Berg and Burger conclude that fairly good targeting of Old Age Pensions and Disability Grants has resulted in rural areas receiving an unusually fair share of social spending compared to the situation in many developing countries. However, they caution that the true impact of more equalised social spending may be less than it appears because of differences in the quality of the services actually provided. For example, while inequalities in educational inputs have narrowed, inequality in educational outcomes have not (van der Berg and Burger, 2002: p. 18).

Data for the period between 2000 and 2004 are limited, but some initial findings suggest that the poverty rate may be on the decline. Van der Berg et al. (2005) use data derived from the All Media and Products Survey (a market research survey) to show a substantial decline in rate, depth and severity of money-metric poverty during the period 2000-4. These same data also show consistently high levels of inequality. Meth (2006) uses data from Statistics South Africa's General Household and Labour Force surveys to critique the results of the marketing survey. However, he concludes that it is likely that there has been a decline in the headcount poverty index, although one that is far more modest than what is suggested by the marketing data.

Summarising these other studies, poverty appears to have persisted in South Africa during the 1990s, with perhaps some improvement since 2000. Inequality remains high and is probably widening. While some have argued that these trends do not take into account changes in the social wage, how to measure the social wage remains unclear. Attempts to measure the social wage suggest that it improves the situation somewhat, but not enough to change the overall tendency.

Reacting to this evidence on poverty and inequality, the South African government has argued that poverty is multi-dimensional, and that success has been achieved in terms of improving the access of poor households to services. Exploring this claim, May and Woolard (2005) provide four indicators of service delivery for the years 1995 and 2003 and compare changes in access by income group. The indicators that they use are the percentage of households with access to piped water (either inside their dwelling or 
Jorge Agüero et al.

on the stand), the percentage of households living in permanent structures, the percentage of households with electricity (from mains) and the percentage of children aged 7-17 enrolled in school.

In the case of access to quality housing, all of the lower income groups experienced marked improvements, with each expenditure group (except the very highest) experiencing an improvement of between 11 and 14 percentage points. In the case of access to electricity, the improvements have been enormous and the three lower expenditure groups have all benefited in a very similar pattern. Improvements in access to piped water have been somewhat less well targeted towards the very poor. Although access to piped water increased from $28 \%$ to $79 \%$ (an increase of 51 percentage points) for the expenditure group R800-R2499, the increase was only 40 percentage points for the lowest income group R0-R399. Finally, in the case of school enrolments, the increases have been highest among the poorest groups. From the perspective of basic service delivery, the gap between the poor and non-poor has narrowed in the post-apartheid era, although it must be cautioned that these data do not comment on the quality of the service, nor on whether the supply of the service has been disconnected. Bhorat et al. (2004) report similar results concerning improved access to services.

Interesting as these trends are, the cross-sectional data on which they are based cannot provide information on the changes experienced by individual households. Thus it is possible that while some households have benefited from the reforms in the post-apartheid period, others may have fallen back either as a result of economic or political reforms, or through broader economic and demographic trends. Panel data are required for this type of analysis and are essential if one is to understand the movements into and out of poverty and the differences between transitory and chronic poverty (e.g., Bane and Elwood, 1986; Hulme and Shepherd, 2003).

Panel studies have the added benefit in that they can provide information on various chains of events, for example, those that might begin when someone first falls sick with AIDS and which extend long after their death (e.g., Yamano and Jayne 2004, and Carter et al., 2006). Finally, panel studies allow one to examine the longer-term effects of economic and demographic changes. Although a national panel survey would be ideal in these circumstances, such a survey has yet to be undertaken in South Africa. However, the trends revealed by KIDS data collected in the KwaZulu-Natal province can help 
improve interpretation of the cross-sectional national data just discussed.

\section{The PSLSD, KIDS 1998 and KIDS 2004}

The PSLSD, undertaken in the second half of 1993, was the first nationally representative household survey in South Africa to investigate poverty, inequality and socio-economic dynamics (PSLSD, 1994). The design of the study was similar to that of the Living Standards Measurement Surveys (LSMS) that have been undertaken in more than 100 developing countries. The main instrument was a comprehensive household survey that collected an array of information on the socio-economic circumstances of households. The 1993 sample was selected using a two-stage self-weighting proportional-to-population design using a sample frame based on the 1985 Census (PSLSD, 1994). An important component of the design was the definition of a household. According to PSLSD, 1994, resident household members were defined as (i) those who had lived '... .under this roof for more than 15 days of the last 30 days; and (ii) when they are together they share food from a common source (i.e., they cook and eat together) and (iii) contribute to or share in, a common resource pool.' The household was also defined to include non-resident members who satisfied conditions (ii) and (iii) but needed only to have lived '... under this roof or within the same compound/homestead/stand at least 15 days out of the past year.'

Households visited by the PSLSD in KwaZulu-Natal province were re-surveyed from March-June 1998 to form the study now known as KIDS (May et al., 2000). In KwaZulu-Natal, the 1993 PSLSD data included 1558 households of all races located in 73 sampling points or clusters. For KIDS in 1998, the white and coloured households were excluded from the sampling frame due to likely sampling biases. Eventually, the matched 1993 and 1998 waves of KIDS contained data on 1,171 African and Indian households of the 1,354 eligible households interviewed in 1993. Eligible households were those in which key decision-makers resided, termed 'core' persons as is documented by May et al. (2000).

As May et al. (2005) detail, the third wave of this panel study was completed in 2004. Using the same approach as in 1998, the households of the core members of the original panel of households were identified for re-survey. Households where cores split during this 
period were followed-up wherever feasible. Both of these households are designated as ' $C$ ' households. In an important addition to the tracking process, the 2004 survey refreshed the panel by interviewing grown-up children of core household members who (i) had established their own households and (ii) had children of their own. These 'next generation' cores are designated as ' $K$ ' households.

In addition, core members' children aged less than 18 and who were being cared for by other households were also tracked, interviewed and are designated as ' $\mathrm{N}$ ' households. These changes mean that unlike in 1998, the household-level response rate in the third wave of KIDS incorporates households interviewed because they had living core members as well as 'dynasties' of the 1993 households where all the core members had disappeared or died but information was obtained from 'next generation' or from fostered children. In total, information is available from 2004 for $74 \%$ of the dynasties contacted in 1998 and $62 \%$ of the households interviewed in 1993.

As discussed in May et al. (2000) and Maluccio (2000), attrition rates of this magnitude raise concerns about bias, as households that remain in the sample might have different characteristics than those that do not. This fact, along with limitations of the original 1993 sampling frame and study imply that the KIDS study is not a fully representative sample of the Africans and Indians living in KwaZulu-Natal, let alone of South Africa in its entirety. While all panel studies become less representative over time, we believe that the KIDS longitudinal data set can throw light on the contested changes in well-being already discussed.

\section{Distribution Dynamics and Changes in Welfare, Evidence from KIDS 1993-2004}

Changes in income and expenditure dynamics remain an important focus of KIDS and, using the new data, this section offers a first look at changing patterns of economic well-being among the KIDS sample over the first decade of post-apartheid South Africa. While interesting in their own right, these numbers are also provocative, demanding explanation for the patterns they portray. Basic data on core well-being distribution dynamics and the evolution of access to basic services are first presented. This section also examines the economic well-being of the now grown children of KIDS households and gives some insights into inter-generational and lifecycle changes. 
Table 2: Poverty Measurement Using Income and Expenditure

\begin{tabular}{lllll}
\hline & & & & \\
& Measure & 1993 & 1998 & 2004 \\
\hline \multirow{3}{*}{ Expenditure } & & & & \\
& FGT-0 & 0.52 & 0.57 & 0.47 \\
& FGT-1 & 0.20 & 0.26 & 0.22 \\
& FGT-2 & 0.09 & 0.14 & 0.12 \\
& FGT-0 & 0.65 & 0.54 & 0.52 \\
& FGT-1 & 0.36 & 0.29 & 0.28 \\
& FGT-2 & 0.24 & 0.28 & 0.20 \\
\hline
\end{tabular}

\subsection{The Evolution of Income and Expenditure Poverty Measure for} the Core KIDS Cohort

As already mentioned, the KIDS data come from repeated surveys of a 1993 cohort of core economic decision-makers. Using only the households of those core people observed in all three time periods, Table 2 reports the standard group of poverty measures developed by Foster et al. (1984). In calculating these measures, a household has been deemed poor if its monthly per-capita expenditures or income (inflated or deflated to 2000 prices) ${ }^{1}$ fell below the poverty line of R322 per month per person suggested for South Africa by Hoogeveen and Özler (2005). ${ }^{2}$

As can be seen in the table, the headcount index of poverty (FGT-0) using expenditure increased from 0.52 in 1993 to 0.57 in 1998, before falling to 0.47 in 2004 . When income is used, the headcount declines continuously from 1993 . The poverty gap index (FGT-1) increases from 0.20 to 0.26 and then declines to 0.22 using expenditure, but also declines continuously when income is used. Finally, the poverty severity index (FGT-2) increases from 0.09 to 0.14 before recovering slightly to 0.12 using expenditures. The income-based measure repeats this pattern. In all cases, the trends between 1998 and 2004 are consistent in terms of both income- and expenditure-based measures.

1 The deflators used were taken from the Consumer Price Index produced by Statistics South Africa for the month in which field work commenced and were 1.605 for $1993,1.143$ for 1998 and 0.812 for 2004 .

2 Hoogeveen and Özler (2005: p.7) suggest several options, and we have chosen to use their 'lower bound' estimate. 
The discrepancy between the trend in the poverty headcount shown by the expenditure-based versus the income-based measure demands explanation. As discussed in Section 2, other studies of the mid-to-late 1990s show an increasing headcount measure of poverty, suggesting that the 1993 income may have been underreported in the data used in this study. Indeed, the 1998 and 2004 KIDS questionnaires were modified modestly in order to ensure more accurate reports of both earned and unearned income. For example, in the later surveys, prompts were used to encourage respondents to report income from economic activities, 'no matter how small or temporary.' The agriculture module was also redesigned and more carefully implemented in the later survey periods.

Another possible explanation for the discrepancy between the income and expenditure measures is that expenditures were overreported in 1993. There is some basis for this possibility. The 1998 and 2004 surveys collected all food expenditure data on a 30-day recall period. In contrast, the 1993 survey allowed respondents to choose between 7-day and 30-day recall periods on a commodityby-commodity basis. In an experimental test of the impact of recall period on expenditure reporting, Scott and Amenuvegbe (1990) found that shorter recall periods lead to higher reported expenditures (also see Tarozzi, forthcoming; Deaton and Grosh, 2000). While forcing a 7-day recall period on low frequency food purchases will logically lead to an over-reporting of these expenditures, it is important to recognise that the 1993 data used in the KIDS study allowed respondents to choose the recall period (a choice that did not exist in the Scott and Amenuvegbe experiment).

Closer analysis of the KIDS 1993 data show that in fact the longer 30 -day recall period was used by over $60 \%$ of respondents for 23 out of the 30 food commodity groupings. The only two commodities for which more than $60 \%$ of respondents used the 7 -day recall period are milk and bread, which are probably really purchased at high frequency. ${ }^{3}$ Deflating those food expenditures reported on a 7-day basis as suggested by the Scott and Amenuvegbe findings does reduce the extent to which expenditure declined between 1993 and 1998 but does not reverse the trend of increasing poverty. ${ }^{4}$

${ }^{3}$ Several fresh fruit categories were also reported using the 7-day recall period in just over half the cases.

4 These results are available from the authors on request. 
While the discrepancy between the income and expenditure measures in 1993 is bothersome, it seems likely that this is not due to the modest changes in the recall period, and rather that 1993 income was under-reported, or that some other explanation must be found for any suspected over-reporting of 1993 expenditures. ${ }^{5}$ In line with the conventional wisdom that expenditures are more accurately measured than earnings for low-income households, we continue to depict household well-being using the expenditure data collected in the survey. That said, although the findings reported here are consistent with most other analyses of poverty in South Africa during the 1990s, there is cause for caution given the troublesome inconsistency between income and expenditure figures over the 1993-1998 period.

\subsection{Poverty Transitions for the Core KIDS Cohort}

While the increasing availability of panel data has spawned new analytical methods and measures (see Carter and Barrett, 2006), transition matrices continue to provide a compelling window into well-being distribution and poverty dynamics. Table 3 shows the transition over the full 1993-2004 period. We normalised the real household expenditure measure, defined as total household expenditures, adjusted to 2000 prices, and divided by the Hoogeveen and Özler poverty line. ${ }^{6}$ A normalised expenditure value equal to 1 thus indicates that household expenditures exactly equal the poverty line for the household. A measure of 2 indicates that household expenditures represent a level of material well-being that is twice the poverty line and so on.

The columns of Table 3 are defined using households' 2004 level of normalised well-being, and permit us to see the fate of each household over the 1993-2004 period. Looking across the first row, 38\% of the households whose 1993 standard of living was less than half the poverty line are just as poor in 2004. Another $34 \%$ of these households have modestly higher standards of living in 2004 (but still below the poverty line). The remaining $28 \%$ of these households now enjoy standards of living in excess

${ }^{5}$ See Cichello et al. (2005) for an alternative explanation using income data.

6 The exchange rate of the South African Rand fluctuated during part of the survey period, and in mid-2000 was equivalent to US\$0.146 compared to US\$0.163 in mid-2004, US\$0.158 in mid-1998 and US\$0.298 in mid-1993. 
Table 3: 1993-2004 Transition Matrix

\begin{tabular}{|c|c|c|c|c|c|c|c|}
\hline 1993 & 2004 & $\begin{array}{l}<0.5 \text { PL } \\
(n=189)\end{array}$ & $\begin{array}{l}<1 \mathrm{PL} \\
(n=222)\end{array}$ & $\begin{array}{l}<1.5 \mathrm{PL} \\
(n=138)\end{array}$ & $\begin{array}{l}<2.0 \mathrm{PL} \\
(n=74)\end{array}$ & $\begin{array}{l}<2.5 \mathrm{PL} \\
(n=47)\end{array}$ & $\begin{array}{l}>2.5 \mathrm{PL} \\
(n=196)\end{array}$ \\
\hline \multirow[t]{4}{*}{$<0.5 \mathrm{PL}(n=129)$} & $\%$ of Row & 38 & 34.1 & 14 & 8.5 & 0 & 5.4 \\
\hline & $\%$ of Column & 25.9 & 19.8 & 13.0 & 14.9 & 0 & 3.6 \\
\hline & $1993 \mathrm{NE}^{\mathrm{a}}$ & 0.4 & 0.4 & 0.4 & 0.4 & 0 & 0.4 \\
\hline & $2004 \mathrm{NE}$ & 0.3 & 0.7 & 1.1 & 1.8 & 0 & 3.6 \\
\hline \multirow[t]{4}{*}{$<1$ PL $(n=317)$} & $\%$ of Row & 26.8 & 31.9 & 21.8 & 7.3 & 3.8 & 8.5 \\
\hline & $\%$ of Column & 45.0 & 45.5 & 50.0 & 31.1 & 25.5 & 13.8 \\
\hline & $1993 \mathrm{NE}$ & 0.7 & 0.7 & 0.7 & 0.7 & 0.8 & 0.8 \\
\hline & $2004 \mathrm{NE}$ & 0.3 & 0.7 & 1.2 & 1.7 & 2.2 & 4.2 \\
\hline \multirow[t]{4}{*}{$<1.5 \mathrm{PL}(n=180)$} & $\%$ of Row & 20.6 & 24.4 & 13.9 & 8.9 & 8.3 & 23.9 \\
\hline & $\%$ of Column & 19.6 & 19.8 & 18.1 & 21.6 & 31.9 & 21.9 \\
\hline & $1993 \mathrm{NE}$ & 1.2 & 1.2 & 1.2 & 1.2 & 1.2 & 1.3 \\
\hline & $2004 \mathrm{NE}$ & 0.3 & 0.7 & 1.2 & 1.7 & 2.2 & 5.2 \\
\hline \multirow[t]{4}{*}{$<2.0 \mathrm{PL}(n=111)$} & $\%$ of Row & 9.9 & 18 & 15.3 & 12.6 & 12.6 & 31.5 \\
\hline & $\%$ of Column & 5.8 & 9.0 & 12.3 & 18.9 & 29.8 & 17.9 \\
\hline & $1993 \mathrm{NE}$ & 1.8 & 1.7 & 1.7 & 1.7 & 1.8 & 1.8 \\
\hline & $2004 \mathrm{NE}$ & 0.4 & 0.8 & 1.2 & 1.8 & 2.2 & 4.9 \\
\hline \multirow[t]{4}{*}{$<2.5 \mathrm{PL}(n=50)$} & $\%$ of Row & 12 & 10 & 6 & 12 & 8 & 52 \\
\hline & $\%$ of Column & 3.2 & 2.5 & 2.2 & 8.1 & 8.5 & 13.3 \\
\hline & $1993 \mathrm{NE}$ & 2.2 & 2.2 & 2 & 2.2 & 2.2 & 2.2 \\
\hline & $2004 \mathrm{NE}$ & 0.4 & 0.7 & 1.1 & 1.8 & 2.2 & 5.6 \\
\hline
\end{tabular}




\begin{tabular}{lllllllr}
$>2.5$ PL $(n=79)$ & \% of Row & 1.3 & 10.1 & 7.6 & 5.1 & 2.5 & 73.4 \\
& \% of Column & 0.5 & 3.6 & 4.3 & 5.4 & 4.3 & 29.6 \\
& 1993 NE & 4.8 & 3.5 & 3 & 3.4 & 3.3 & 5.2 \\
& 2004 NE & 0.3 & 0.7 & 1.3 & 1.9 & 2.3 & 8.4 \\
\hline
\end{tabular}

${ }^{a} \mathrm{NE}$ indicates real per-capita expenditures that have been normalised by the Hoogeveen and Özler (2005) poverty line. The comparison relevant for this analysis is between a 1993 NE number and the 2004 NE. 
796 Jorge Agüero et al.

of the poverty line. The column percentages show that the bulk of those below the poverty line in 2004 come from those who were poor or near poor in 1993.

In addition to the percentages of households in a specific transition category, each cell of the table reports the average 1993 and 2004 standardised expenditures for households in the cell. For example, the households that made the transition from less than half the poverty line to more than 2.5 times the poverty line had average expenditures equal to $40 \%$ of the poverty line in 1993, and equal to 3.6 times the poverty line in 2004. Finally, the main diagonal elements of the transition matrix are highlighted in bold and show the fraction of households in each row that have not changed their well-being category. For example, $73.4 \%$ of households that had living standards in excess of 2.5 times the poverty line in 1993 were still above that level in 2004.

As a number of authors have recognised, mobility measures, such as the ones presented here, are potentially biased upwards due to measurement errors in the underlying data. When expenditures are measured with errors (due to misreporting or coding error), the observed data have 'noise' added to them. Stable households that did not really change their economic position may thus appear to exhibit mobility (up or down) because of measurement error.

Glewwe (2005) proposes a methodology for uncovering the degree to which overall observed mobility is the result of measurement error. Following Glewwe, we used health-related measures at the household level as instruments for household living standards and find that measurement error in one or more of the waves accounts for at least $14 \%$ of all mobility and could account for as much as 60\% of mobility between 1993 and 1998. This situation is less extreme for the 1993-2004 period as measurement error accounts for not more than $4 \%$ of mobility between 1998 and 2004. Unfortunately, these estimates of the degree of mobility bias are not robust to changes in the specification. Efforts beyond the scope of this paper are needed to better understand this difficult issue. Nonetheless, these issues do suggest that a significant portion of the observed mobility (especially in the first time-period) may be subject to measurement error.

As an alternative and simpler approach that does not depict the degree of mobility, Table 4 records the percentage of core households broken down by the number of poverty spells that they 
Table 4: Chronic and Transitory Poverty ${ }^{\mathrm{a}}$

$\begin{array}{lrr}\text { P-P-P } & 34.9 & 27.9 \\ \text { P-P-N } & 11.0 & 12.5 \\ \text { P-N-P } & 8.4 & 4.3 \\ \text { P-N-N } & 10.5 & 6.9 \\ \text { N-P-P } & 3.7 & 10.3 \\ \text { N-P-N } & 4.0 & 6.6 \\ \text { N-N-P } & 4.6 & 5.0 \\ \text { N-N-N } & 22.8 & 26.6\end{array}$

${ }^{\mathrm{a}} \mathrm{P}$, poor; N, not poor.

have experienced, showing this information for expenditure and for income.

While the mobility reported in both Tables 3 and 4 is likely overstated, they together suggest the following patterns of mobility in the KIDS data:

Chronic and Transitory Poverty: Using the KIDS expenditure measures, $28 \%$ of households were chronically poor as defined by Hulme and Shepherd, 2003, meaning that they were recorded as being poor in all three waves. Put differently, 53\% of households that were poor in 1993 were poor in 1998 and were still poor in 2004. At the same time, there is some upward mobility among those who were initially poor, although there is also substantial downward mobility $(53 \%)$ among those just above the poverty line. The result is that $45 \%$ ( $42 \%$ if using income) of the households can be thought of as transitorily poor. ${ }^{8}$ These figures are consistent with the existence of a core group of persistently poor people, surrounded by a somewhat larger group of sometimes poor who move in and out of poverty over time: the transitory poor. This is an argument made earlier by Carter and May (2001), although it

${ }_{8}^{7}$ This figure is somewhat higher using an income-based poverty measure.

8 A useful feature of Table 4 is that although generally similar results are found when using income or expenditure, the N-P-P group is noticeably different, confirming that either the 1993 income was under-stated or the 1993 expenditure was over-stated. 


\section{Jorge Agüero et al.}

suggests a greater mobility around the poverty line over the longer period. Finally, $27 \%$ of households were never recorded as being poor in terms of their expenditure ( $23 \%$ if income is used).

Instability and Bifurcation among the Nearly Poor: The expenditure group just above the poverty line appears to be quite unstable. Some $41 \%$ of households that had expenditures between 1.0 and 1.5 times the poverty line in 1993 enjoyed expenditures more than 1.5 times the poverty line in 2004. Another $44 \%$ of these households had fallen below the poverty line in 2004, and $14 \%$ had maintained their position. This pattern of bifurcation (with some households slipping down, perhaps to a low level equilibrium, and others rising, perhaps toward a high level equilibrium) is partially consistent with the pattern identified by Adato et al. (2006). Analysing asset dynamics using the 1993-8 KIDS data, these authors identify a critical asset threshold that divides those predicted to fall back into poverty from those predicted to accumulate and move ahead over time.

Real Expenditure Growth at the Top of the Expenditure Distribution: Consistent with studies of the earlier rounds of the KIDS data, those households who were well above the poverty line in 1993 largely maintained their positions or moved ahead over time. On average, households that had expenditures more than 2.5 times the poverty line in 1993 experienced an increase in expenditure of $61 \%$ over the 11 years of the study. More than $44 \%$ of the households that had expenditures in 1993 between 1.5 and 2.0 times the poverty line moved ahead substantially over time and mean expenditure of this group grew by a massive $160 \%$. Consistent with the dynamic analysis of Adato et al. (2006), there is little downward mobility among these better-off groups compared to the nearly-poor group.

Not surprisingly, the combined effect of these mobility patterns is an increase in expenditure inequality, a finding consistent with those of Hoogeveen and Özler (2004) and many others analysing South Africa's income and expenditure distribution since 1993. Among the KIDS households, the Gini coefficient measure of inequality in the distribution of household expenditures has risen steadily from 0.42 in 1993 to 0.50 in 1998 and to a remarkably high 0.57 by 2004. As discussed by Carter and May (2001), this increase in inequality is neither surprising nor an unambiguously bad thing, although May et al. (2004) caution that at some point 

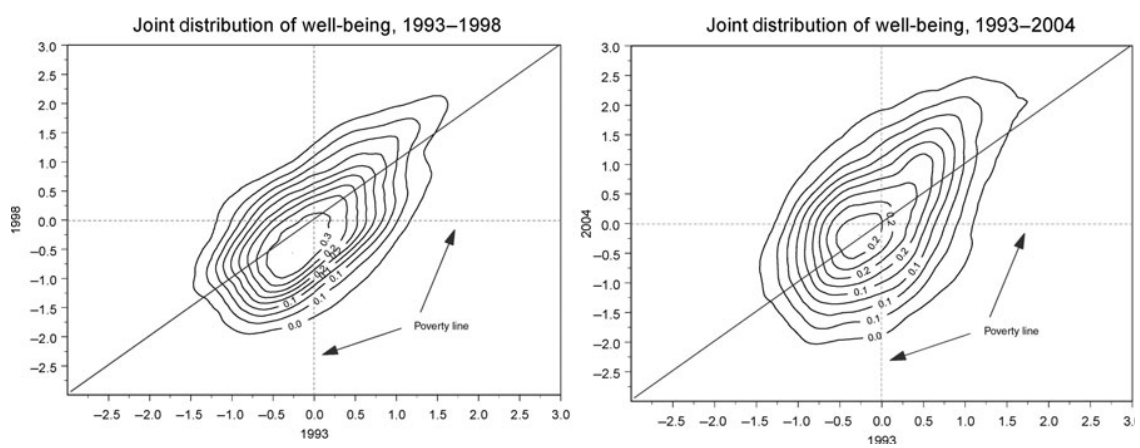

Figure 1: Joint Distribution of Well-Being: 1993, 1998, 2004

high levels of inequality may impact upon economic growth rates and social stability.

While Table 2 presents an overall picture of the evolution of economic well-being for a cohort of KwaZulu-Natal households over the first decade of the post-apartheid economy, the KIDS data permit us a closer look at that history by decomposing it into two sub-periods. As analysed elsewhere (May et al., 2000; Carter and May, 2001), the 1993-8 period saw substantial increases in poverty and slippages at the bottom end of the distribution, with substantially more improvement at the top end of the distribution. The 1998-2004 period saw some moderation in this trend.

As an alternative way of illustrating this, Figure 1 provides contour graphs showing the joint distribution of well-being for two of the pair-wise comparisons that are possible ('93 with '98; '93 with '04). These graphs may be thought of as mobility planes, and as with the transition matrix, the axes refer to a normalised expenditure measure. In this instance, the $x$-axis uses a logarithmic scale to display a household's 1993 consumption as a percentage of its subsistence needs. Prior to estimating the joint distribution of well-being, we re-scaled the data by taking the natural logarithm of the expenditure per-capita measures used in the prior analysis. ${ }^{9}$ The spread of the contours reflects the distribution of well-being.

${ }^{9}$ As has often been noted, income distribution is approximately log-normally distributed and taking the logs, as we have done here, re-scales the data so that our non-parametric kernel estimator can adequately represent the shape of the joint distribution. Because of this re-scaling, a household whose per-capita expenditures exactly equal the poverty line will have a well-being value of zero. Positive values indicate well-being levels above the poverty line, negative values signal living standards below the poverty line. The southeast (or 
The overall picture is that the 1998-2004 transition undid some of the downward movement seen in the 1993-8 transition and documented by Carter and May (2001). In contrast to the the 1993-8 period, the mode of 1993-2004 joint distribution lies to the northwest of the $45^{\circ}$ line and the distribution is more symmetric, suggesting that there has been an improvement in upward mobility for those close to the poverty line. Nonetheless, there is still plenty of spread indicating downward mobility and transitory poverty for many, as well as widening inequality. We will return to this mode of analysis to examine the impact of grants on the distribution of well-being.

In summary, the poverty and income distribution dynamics displayed by the KIDS data are complex. A number of possible reasons could explain the evolving distribution of economic wellbeing seen in the KIDS sample. After looking at other indicators of the well-being of the core KIDS cohort, and of their now grown-up children, we will return at the end of this section to consider these alternative reasons.

\subsection{Household Services and Basic Human Needs}

Improvements in the delivery of services have been identified by Statistics South Africa as an important achievement of the postapartheid government (Stats SA, 2002). As is shown in Table 5, positive changes have also taken place in access of the surveyed households to the set of basic needs indicators gathered by all three waves of KIDS.

The most notable progress is in electricity connections, which improved between 1993 and 2004, from being available to $43 \%$ of the sample to $75 \%$. This is followed by the percentage of the sampled households who live in formal housing, which increases from 67 to $85 \%$ of the sample. Improvements in access to piped water have been more modest, while the percentage of households with access to a toilet in the dwelling or on the stand inexplicably

bottom left) quadrant in the figure thus contains households who are twice poor, and who might be thought of as being chronically poor, again in the manner described by Hulme and Shepherd (2003). The top left and bottom right quadrants are the transitory poor, while the top right are the never poor. Finally, note that the $45^{\circ}$ line drawn across the figure represents positions of no change. A position above the $45^{\circ}$ line represents upward mobility, while positions below the line show downward mobility. 
Table 5: Basic Needs Indicators for Core KIDS Households

\begin{tabular}{lllllll}
\hline Year & $\begin{array}{l}\text { Have } \\
\text { electricity } \\
\text { connection }\end{array}$ & $\begin{array}{l}\text { Live in } \\
\text { formal } \\
\text { house }\end{array}$ & $\begin{array}{l}\text { Piped } \\
\text { water } \\
\text { supply }\end{array}$ & $\begin{array}{l}\text { Toilet } \\
\text { on stand }\end{array}$ & $\begin{array}{l}\text { Own } \\
\text { house }\end{array}$ & $\begin{array}{l}\text { Median } \\
\text { people/ } \\
\text { room }\end{array}$ \\
\hline & & & & & & \\
1993 & 42.5 & 67.3 & 37.2 & 76.6 & 87.0 & 1.4 \\
1998 & 64.8 & $\mathrm{n} / \mathrm{a}$ & 41.5 & 67.2 & 88.7 & 1.2 \\
2004 & 74.5 & 85.2 & 50.7 & 86.3 & 90.4 & 1.0 \\
\hline
\end{tabular}

declines between 1993 and 1998, perhaps due to definitional changes during fieldwork, before increasing to $86 \%$ of the sample. Finally, some progress has also been made in the percentage of households who report owning their house and in room density, measured as the median number of people per room.

While the overall picture is quite positive, some caution is in order. Information was not gathered concerning whether utility connections were operative, or whether they had been shut off. Also, home ownership may be less positive than it appears as the tenure rights involved may mean that the building cannot be sold nor used as collateral. Nonetheless, the picture suggested by the KIDS data concerning services is one progress in a number of the key goals outlined by the Reconstruction and Development Programme (RDP) in 1994.

\subsection{KIDS: the Next Generation}

While the prior sections have analysed the households of the 1993 core survey respondents, we might wonder whether the next generationthe now grown-up children of the original core respondents-are doing better or worse than their parents. Approximately two-thirds of the core households contained in the KIDS 2004 sample had grown-up children about whom we were able to obtain information. Some of these grown-up children have established independent residences (and were interviewed as ' $K$ ' households, as discussed earlier). Others continue to reside in the households of their parents. The KIDS data do not permit us to distinguish the living standards 
802 Jorge Agüero et al.

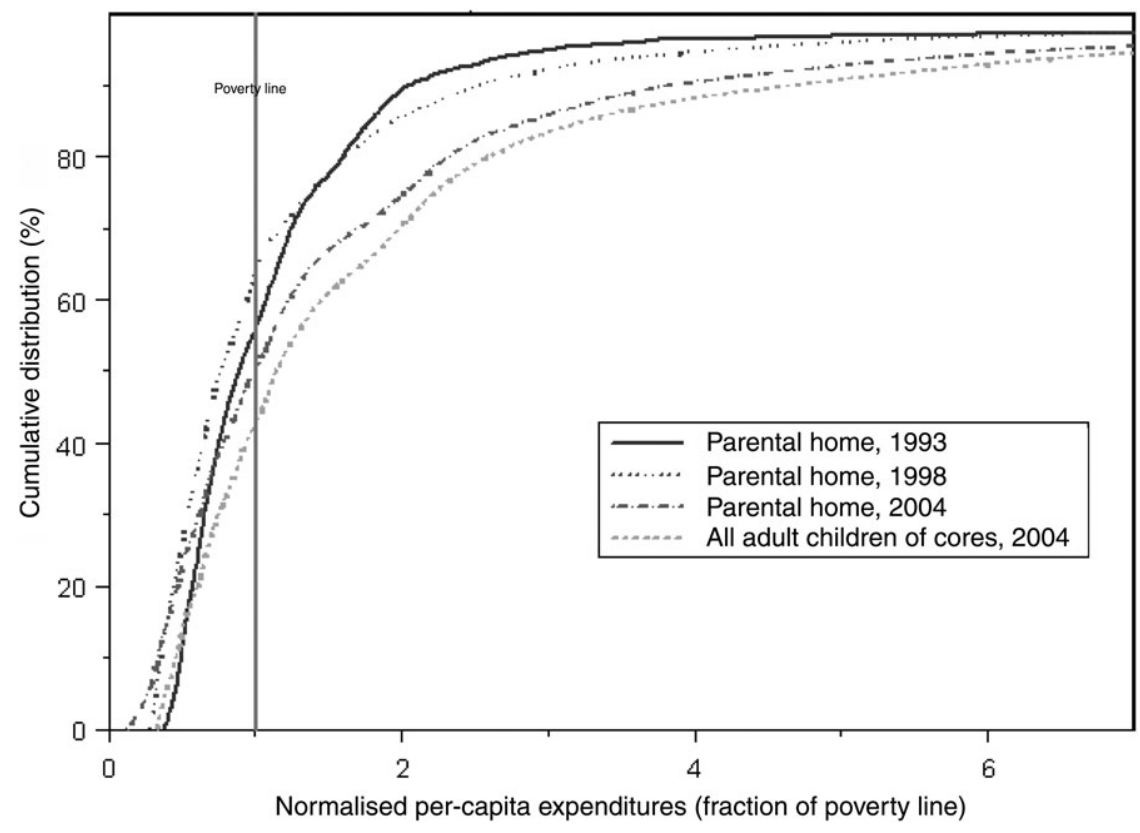

Figure 2: Cumulative Expenditure Distribution: 1993-2004

of this latter group from that of their parents. We first combine these two groups of grown-up children and examine their level of wellbeing compared to that of their parents.

Figure 2 graphs cumulative density functions (CDFs) for normalised per-capita expenditures for grown-up children and for the core or parent households from which they emerged. ${ }^{10}$

Consistent with the analysis in the prior section, the CDFs for the parents shows an increase in poverty from 1993 to 1998, and then a reversal of this trend from 1998 to $2004 .^{11}$ However, as can be seen, the CDF for the next generation lies everywhere to the southeast of the $2004 \mathrm{CDF}$ for the parents, indicating that the next generation is doing better than their parents. Given that slightly more than half of the next generation grown-up children live with their parents, and

10 Only data on those grown-up children who still had at least one core parent alive in 2004 are used to create the figure.

11 Statistically, we cannot reject the hypothesis that core households with grown-up children have the same expenditure distribution as all core households based on Kolmogorov-Smirnov tests. 
have the same recorded living standard as their parents, Figure 2 suggests that the segment of the next generation that has established independent residences is likely doing even better than Figure 2 would indicate. In order to explore this issue, Figure 3 compares the CDF for this group with the next generation sub-cohort that continues to live with their parents. As can be seen, the former group is much better-off than the latter.

There are several possible explanations for the differences between these two groups. First, it may be that grown-up children with independent residences are better educated and otherwise more successful economically. Alternatively, it could be that grown-up children still at home have family responsibilities that keep them at home (to support parents or other needy family members). Table 6 takes a first look at the differences between these two next generation groups.

As can be seen, the next-generation individuals who have an independent residence are more educated than those who did not, they are also a little older and, on average, received fewer shocks (both negative and positive). They also tend to have a

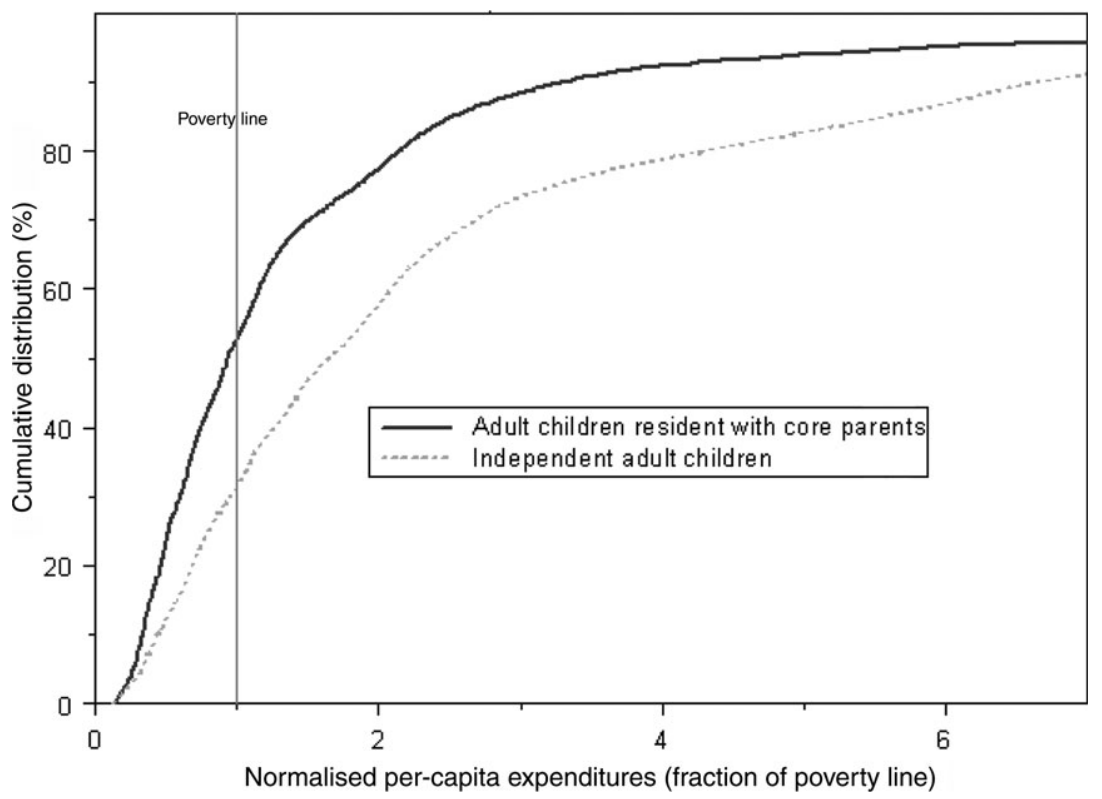

Figure 3: Economic Well-Being of the Next Generation 
804 Jorge Agüero et al.

Table 6: Characteristics of Independent versus Non-independent Grown-up Children

Characteristics

Non-independent

Independent

residence

Years of schooling

$8.9^{\mathrm{a}}$

9.8

Proportion with tertiary education

$0.06^{\mathrm{a}}$

0.1

Proportion with matric

$0.3^{\mathrm{a}}$

0.4

Age

$33.7^{\mathrm{a}}$

35.7

Formally employed (\%)

$9.0^{\mathrm{a}}$

31.0

Median monthly wages

2600

2800

Number of negative shocks last 6 years

Number of positive shocks last 6 yeas

1.2

0.9

$1.0^{\mathrm{a}}$

0.8

${ }^{a}$ Differences are statistically significant.

substantially higher labour participation rate. Hence, human capital differences, employment and less exposure to risk may explain why the ones who moved out got ahead in 2004. These findings lend support to other findings from South Africa that the formation and splitting-off of new households may sometimes be endogenous (Case and Deaton, 1998; Klasen and Woolard, 2001). There is thus at least some evidence that the next generation, like their parents, is bifurcating into two distinct groups. Additional analysis of this topic, especially concerning whether parents' status is transmitted to their children, is clearly required.

\section{KIDS: the Impact of Government Transfers}

While the income distribution dynamics revealed by the KIDS data are complex, underlying the dynamics are a mix of both market outcomes and the redistributive impact of government taxes and transfers. In order to take a look at the impact of government programs on the well-being of the KIDS households (and especially on the improvements in the lower end of the income distribution seen between 1998 and 2004), we formed an expenditure measure purged of the effects of government transfers and taxes. We did this by taking measured expenditures, subtracting out government 
transfers (Old Age Pensions, the child support grant, etc.) and then adding back in taxes that were reported paid (municipal rates plus reported payroll taxes). The value of housing or other such subsidies has not been netted out. In a few cases, this procedure resulted in households having negative net pre-transfer expenditures. Clearly, households could not have negative expenditures, indicating that expenditures were likely under-reported for these households. For these cases, pre-transfer expenditures were set to zero (i.e., we added back in the amount of the likely minimum reporting error). In an effort to maintain comparability across our sample, we augmented the pre-transfer expenditures of all other households by the amount of the median reporting error for the negative expenditure households.

This adjusted expenditure measure is similar to what Atkinson (1999) devised to distinguish the role of market forces versus government in driving increasing inequality in the OECD countries. Atkinson argues that market forces are driving large increases in inequality, and that while the reduction of government benefits explains some of the increase, he suggests that other dynamics play a role. He looks at this by graphing over time the true Gini versus the market-based Gini. The difference between the two at any point in time gives the net effect of government on inequality.

A major caveat needs to be made about this method. In netting out the government, we are doing a purely accounting procedure and in no way do we account for the behavioural effects of government programs. So, for example, it is very unlikely that households whose expenditures are less than or equal to the government transfers would do nothing if those transfers did not exist. Presumably, they would try to work more, get more help from family and so forth. In addition, by netting transfers out of expenditure rather than income, we are assuming that the households spend all of these transfers, and do not save or remit the money that they receive. The net effect of ignoring endogenous labour supply and other responses to government programs is that we tend to overstate the effect of government on the progressivity of the distribution. Nonetheless, with this warning, it is still interesting to see the role of government programs in this way.

The values in Table 7 reveal a sharp upward drift in marketgenerated inequality (subject to the caveats above) that is in line with global patterns of inequality. This upward drift is offset to 
806 Jorge Agüero et al.

Table 7: Gini Coefficient of Actual and Market Expenditure ${ }^{12}$

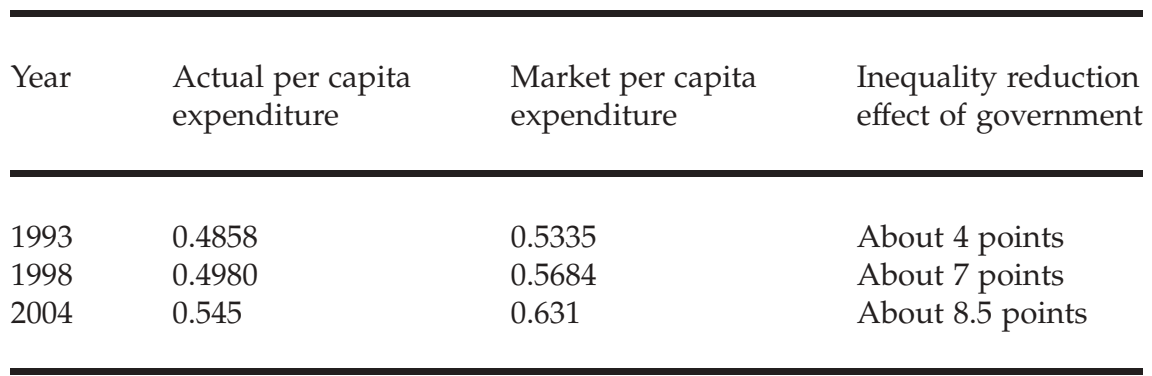

some extent by the increasing inequality reduction effect achieved by the South African government through transfers and taxes. It is noteworthy that the biggest change in this effect took place between 1993 and 1998 which points towards improvements in the amount and coverage of the Old Age Pension that were initiated after the 1993 survey. Overall, the correlation between grants received and our market-generated expenditure measure is -0.30 , suggesting that the system works in a progressive way despite limited means-based targeting of the Old Age Pension.

We now return to the type mobility graphs described earlier to examine what mobility would have looked like without the change in government programs. In Figure 4, the right hand side graph is subject to the weakness discussed earlier in that it assumes no change in behaviour even if government policies were to change.

Comparing the actual with the market-generated expenditure distribution reveals the overall progressive impact of government programs on poverty. Without these programs, the mode of the joint expenditure distribution sits right on the $45^{\circ}$ line, indicating no change between 1998 and 2004. Given that 1998 distribution already represented a significant deterioration from 1993 distribution, this outcome would have signalled continuing high poverty rates. Bringing back in government programs pushes the mode of the joint distribution back across the $45^{\circ}$ line, signalling the distributional improvements discussed earlier. More generally, government transfers do seem to reduce the spread of the

12 If only transfers are netted out and taxes and rates are not added back, the Gini co-efficient for market per capita-expenditure is 0.613 , still indicating a substantial redistributive impact of government transfers. 

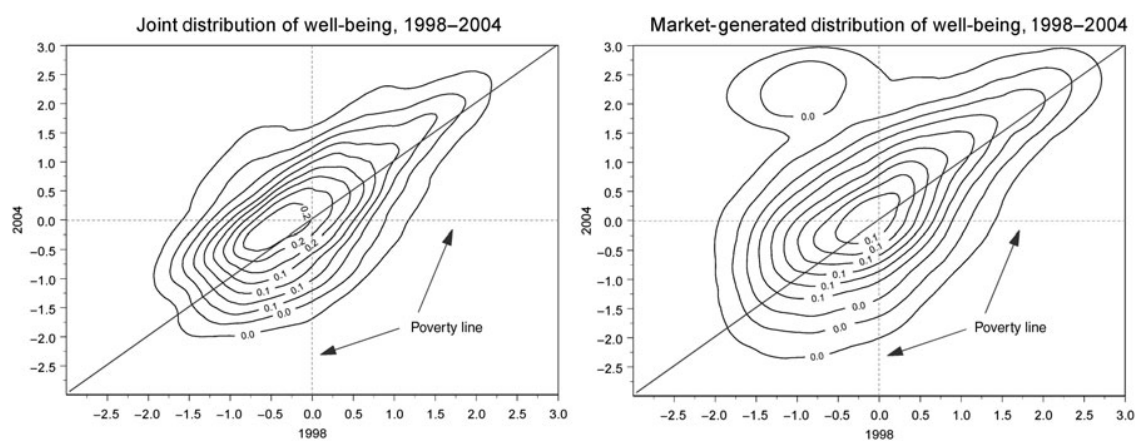

Figure 4: Actual and Market Generated Joint Distribution of Well-Being

expenditure distribution and lift up the very lowest part of the distribution in the poor-poor quadrant, supporting the analysis of van der Berg and Louw (2003) discussed earlier.

\section{Conclusion}

Trends in poverty during the first 10 years of South Africa's democracy have been obscured by the absence of a suitable and regular official poverty study and by poor data collection and processing of the official statistics that are available. Nonetheless, most studies, using both these and other national data, point to an increase in money-metric poverty until 2000. Data are scarce for the period subsequent to this, but it seems possible that this trend has at last been reversed, and that at least the poverty headcount index declined between 2000 and 2004.

Although a comprehensive review of the different methodologies would be helpful, as would the introduction of a specialised poverty and inequality study, other data sources can also shed light on the actual changes that occurred between 1993 and 2004. Panel data in which the same households are re-interviewed are an useful source of information since these studies can reveal what has happened to individuals and households over time. Although no longer the only panel study in South Africa, and confined only to African and Indian households in KwaZulu-Natal, the KIDS database is unique in that the first wave of data collection predates the democratic elections in 1994. 
808 Jorge Agüero et al.

In common with most national findings, the pattern of expenditure distribution among the KIDS cohort is one of increasing poverty and inequality in the mid-1990s. That said, there has been a partial reversal of some of these trends in the post-1998 period, with a decline in the headcount index to below the 1993 levels, and a recovery in the poverty gap and poverty severity indices, a trend also observed in recent national studies. Nonetheless, as with national data, inequality continues to rise. Also somewhat positive is the improved well-being of at least some next-generation households, although those of the next generation who have been unable to accumulate sufficient human capital and have been unable to obtain employment remain in poor households with their parents, perhaps trapped there unless their circumstances change.

There are a number of possible explanations for these trends. First, government expenditure on transfer payments increased throughout the post-apartheid period, while the introduction of the Child Support Grant has dramatically increased the number of recipients of such grants. This is partly reflected in the KIDS data, which show that the amount of transfers per household have doubled, although some of the explanation will no doubt lie with the overall ageing of the cohort. A simple accounting exercise using the KIDS data reveals that these grants have contributed towards dampening the impact of market-generated inequality. In addition to public action, a second area for analysis is on the operation of the markets, particularly the labour market and the expansion or contraction of employment and change in wages for skilled as compared to less-skilled workers.

In line with national data, KIDS also reports a substantial improvement in access to services, which may have enabled other improvements in well-being. This might include the reduction of the time poverty observed by Carter and May (1999), improved health status leading to improvements in the capacity for work, and income generating activities facilitated by access to services such as electricity. Fruitful avenues for future research then include: carefully measuring the impact of the government transfers; investigating long-term mobility and its causes; examining inter-generational poverty and mobility trends; working the multiplier impact of the provision of services; and finally untangling the impact of household formation and fragmentation on well-being. 
Although it was never intended to become a panel survey, the effort put into the design of the original PSLSD has enabled an important and unique data resource to be developed for socio-economic and demographic analysis that remains relevant a decade after the data were first gathered. The updated three-wave KIDS data were placed into the public domain in June 2006 and can be downloaded at no cost from http://sds.ukzn.ac.za/.

\section{References}

Adato, M., M.R. Carter and J. May (2006) 'Exploring Poverty Traps and Social Exclusion in South Africa using Qualitative and Quantitative Data', Journal of Development Studies, 42 (2): 226-47. Atkinson, A.B. (1999) 'Is Rising Income Inequality Inevitable? A Critique of the Transatlantic Consensus', 1999 WIDER Annual Lecture downloaded from http://www.wider.unu. edu/events/ annuel1999.htm on 15 October, 2005.

Bane, M.J. and D.T. Ellwood (1986) 'Slipping Into and Out of Poverty, the Dynamics of Spells', Journal of Human Resources, 21 (1): 1-23.

Bhorat, H., L. Poswell and P. Naidoo (2004) 'Dimensions of Poverty in Post-Apartheid South Africa, 1996-2001, A Poverty Status Report', Development Policy Research Unit, University of Cape Town.

Carter, M.R. and J. May (1999) 'Poverty, Livelihood and Class in Rural South Africa', World Development, 27 (1): 1-20.

Carter, M.R. and J. May (2001) 'One Kind of Freedom: Poverty Dynamics in Post-Apartheid South Africa', World Development, 29 (12): 1987-2006.

Carter, M.R. and C. Barrett (2006) 'The Economics of Poverty Traps and Persistent Poverty: An Asset-based Approach', Journal of Development Studies, 42 (2): 178-199.

Carter, M.R., J. May, J. Agüero and S. Ravindranath (2006) 'The Economic Impact of Severe Illness and Prime Age Mortality: Evidence from Panel Data from KwaZulu-Natal, South Africa', mimeo, University of Wisconsin.

Case, A and Deaton, A. (1998) 'Large Cash Transfers to the Elderly in South Africa', Economic Journal, 108 (450): 1330-61. 
810 Jorge Agüero et al.

Cichello, P., G. Fields and M. Leibbrandt (2005) 'Earnings and Employment Dynamics for Africans in Post-Apartheid KwaZulu-Natal: A Panel Study of KwaZulu-Natal', Journal of African Economies, 14 (2): 143-190.

Deaton, A. and M. Grosh (2000) 'Consumption' in M. Grosh, and P. Glewwe (eds), Designing Household Survey Questionnaires for Developing Countries: Lessons from 15 Years of the Living Standards Measurement Study, Vol. 1, Chap. 5, pp. 91-133. Oxford University Press for the World Bank.

Dorrington, R., T.A. Moultrie and I.M. Timæus (2004) 'Estimation of Mortality Using the South African Census 2001 Data', Centre for Actuarial Research Monograph No. 11. Cape Town: University of Cape Town, http://www.commerce.uct.ac.za/care/Monographs/ Monographs/Mono11.pdf.

Fedderke J.W., J. Manga and F. Pirouz (2003) 'Challenging Cassandra: Household and Per Capita Household Income Distribution in the October Household Surveys 1995-1999: Income and Expenditure Surveys 1995 \& 2000 and the Labour Force Survey 2000', Unpublished mimeograph, University of the Witwatersrand.

Foster, J., J. Greer and E. Thorbecke (1984) 'A Class of Decomposable Poverty Measures', Econometrica, 52: 761-65.

Glewwe, P. (2005) 'How Much of Observed Economic Mobility Is Measurement Error? A Method to Remove Measurement Error Bias, with an Application to Vietnam', mimeo, University of Minnesota.

Hoogeveen, J.G. and B. Özler (2005) 'Not Separate, not Equal: Poverty and Inequality in Post-Apartheid South Africa'. William Davidson Institute Working Paper No. 739. Ann Arbor: University of Michigan.

Hulme, D. and A. Shepherd (2003) 'Conceptualizing Chronic Poverty', World Development, 21 (3): 403-25.

Klasen, S. and I. Woolard (2001) 'Surviving Unemployment Without State Support: Unemployment and Household Formation in South Africa', Sonderforschungsbereich 386: Analyse Diskreter Strukturen, Discussion Paper No. 213. University of Munich.

Maluccio, J.A. (2000) Attrition in the KwaZulu-Natal Income Dynamics Study 1993-1998. Food Consumption and Nutrition Division 
Discussion Paper No. 95. Washington D.C.: International Food Policy Research Institute.

May, J. and B. Roberts (2001) 'Panel Data and Policy Analysis in South Africa: Taking a Long View', Social Dynamics, 27 (1): 96-119.

May, J. and I. Woolard (2005) 'The State of Underdevelopment in South Africa, 1995-2005', Research Report Paper Prepared for the Development Bank of Southern Africa, School of Development Studies, University of KwaZulu-Natal.

May, J., M.R. Carter and V. Padaychee (2004) 'Is Poverty and Inequality Leading to Poor Growth', South African Labour Bulletin, 28 (2): 18-20.

May, J., M.R. Carter, L. Haddad and J. Maluccio (2000) 'KwaZuluNatal Income Dynamics Study (KIDS) 1993-1998: A Longitudinal Household Data Set for South African Policy Analysis', Development Southern Africa, 17 (4): 567-581.

May, J., J. Agüero, M.R. Carter and I.M. Timæus (2005) 'The KwaZulu-Natal Income Dynamics Study (KIDS) 3rd Wave: Methods, First Findings and an Agenda for Future Research', Working Paper.

Meth, C. (2004) 'What has Happened to Poverty in South Africa as Unemployment has Increased?', (Version 5), Draft Manuscript, School of Development Studies, University of KwaZulu-Natal. September 2004, Referred to as Meth (2004).

Meth, C. (2006) 'What was the Poverty Headcount in 2004? A critique of the Latest Offering from van der Berg et al.', Unpublished Research Paper, School of Development Studies, University of KwaZulu-Natal.

Meth, C. and R. Dias (2004) 'Increases in Poverty in South Africa, 1999-2002', Development Southern Africa, 21 (1), 59-86.

PSLSD (1994) Project for Statistics on Living Standards and Development: South Africans Rich and Poor: Baseline Household Statistics. Cape Town, South Africa: South African Labour and Development Research Unit, University of Cape Town.

Simkins, C. (2004) 'What Happened to the Distribution of Income in South Africa Between 1995 and 2001?', downloaded from http:// www.sarpn.org.za/documents/d0001062/index.php on 01 March, 2005. 
812 Jorge Agüero et al.

Scott, C. and B. Amenuvegbe (1990) 'Effects of Recall Duration on Reporting of Household Expenditures: An Experimental Study in Ghana', Social Dimensions of Adjustment in Sub-Saharan Africa. Working Paper No.6, Washington, D.C., The World Bank.

Stats, S.A. (2002) Earning and Spending in South Africa. Selected Findings and Comparisons from theIncome and Expenditure Surveys of October 1995 and October 2000. Pretoria: Statistics South Africa.

Tarozzi, A. (2007) 'Calculating Comparable Statistics from Incomparable Surveys, with an Application to Poverty in India', Journal of Business and Economic Statistics, 25 (3), 314-336.

UNDP (2003) Human Development Report for South Africa, Pretoria, South Africa: United Nations Development Programme.

UNDP (2006) Development Indicators, downloaded on 30/09/06 from http://hdr.undp.org/statistics/data/indicators.cfm?alpha=yes.

van der Berg, S. and R. Burger (2002) 'The Stories Behind the Numbers: An Investigation of Efforts to Deliver Services to the South African poor', Report prepared for the World Bank, University of Stellenbosch, Stellenbosch.

van der Berg, S. and M. Louw (2003) 'Changing Patterns of South African Income Distribution: Towards Time Series Estimates of Distribution and Poverty', paper to the Conference of the Economic Society of South Africa, Stellenbosch, 17-19 September, 2003.

van der Berg, S., Burger, R., Louw, M. and D. Yu (2005) 'Trends in Poverty and Inequality Since the Political Transition', Stellenbosch Economic Working Papers, 1/2005, University of Stellenbosch, downloaded from http://www.ber.sun.ac.za/ downloads/2005/working_papers/WP-01-2005.pdf on 17 January, 2006.

Yamano, T. and T.S. Jayne (2004) 'Measuring the Impacts of Working-age Adult Death on Rural Households in Kenya', World Development, 32: 91-119. 